\title{
PREVALENCE AND RISK FACTORS FOR VOICE PROBLEMS AMONG SOCCER COACHES
}

\author{
D. Fellman ${ }^{1} \&$ S. Simberg ${ }^{1,2}$ \\ ${ }^{1}$ Faculty of Arts, Psychology and Theology, Åbo Akademi University, Åbo, Finland. \\ ${ }^{2}$ Department of Special Needs Education, Faculty of Educational Sciences, University of \\ Oslo, Norway.
}

E-mail: daniel.fellman@ abo.fi, susanna.simberg@abo.fi

Daniel Fellman, tel: +358 505289450

+3584455528875 


\begin{abstract}
Objectives: The prevalence of voice problems has been investigated in various occupations, but research investigating sport coaches' voice problems seems to be limited even if coaches are an occupational group whose work requires heavy voice use. The aim of this study was to determine the prevalence of voice problems among soccer coaches and identify risk factors which can contribute to the problems.

Methods/Design: The data were collected with a web questionnaire that was sent to 500 soccer coaches. Overall, 109 males, who practiced soccer coaching to various extents, responded to the questionnaire. The presence of six vocal symptoms was investigated as well as environmental factors and health related factors that may have an influence on the voice.

Results: The results showed that the prevalence of voice problems among soccer coaches was high. In total, $28.4 \%$ of the participants reported two or more frequently occurring vocal symptoms. The most common symptom was throat clearing or coughing followed by the voice becomes low or hoarse. The coaches who had vocally demanding main occupations alongside their coaching tasks had an increased risk for voice problems. Moreover, a significant association was found between chronic rhinitis and frequently occurring vocal symptoms as well as between stress and frequently occurring vocal symptoms.

Conclusions: Given the extent of voice problems and the fact that soccer coaches have a vocally demanding occupation, it would be important to increase the awareness of voice use among this group. Soccer coaches are in immense need of more information about voice ergonomics during their coaching education.
\end{abstract}

Keywords: voice problems, prevalence, soccer coaches, risk factors 


\section{INTRODUCTION}

In vocally demanding occupations such as teachers, fitness instructors and priests, vocal health is an important factor. ${ }^{1-3}$ Voice problems can have a large impact on people's ability to work and on their quality of life. ${ }^{4}$ Said problems may consequently lead to inability to work which leads to sick leave and thus increased financial costs for the community. ${ }^{4,5}$ Voice problems can also lead to depression and poor self-confidence. ${ }^{4}$ If the problems turn chronic, re-education might be necessary. ${ }^{6}$

The etiology of voice problems is multifactorial. A certain genetic basis has been observed, ${ }^{7,8}$ but the greatest risks are considered to be vocal loading factors in the environment, such as loud background noise, poor room acoustics and poor air quality. ${ }^{1,9-12}$ General health issues, such as poor respiratory health and poor life style habits have been shown to contribute to voice problems. ${ }^{10,13,14}$ Demographic aspects, such as gender, ${ }^{4,6,15}$ and psychosocial factrs ${ }^{10}$ also have an impact on voice problems.

Sports coaches are an occupational group whose work requires heavy voice use. Communication between the coach and the players is usually performed in group situations in which the coach has to speak for long periods of time without interruption. Many sports are practiced outdoors where the background noise often is high and the distance between the coach and the players is long. Also weather elements, such as rain and wind affect the audibility of the voice. Such issues complicate communication and are not conducive to good voice production. ${ }^{16,17}$

Sports coaches work can be very stressful and emotionally demanding, especially during matches or competitions. ${ }^{18}$ Sports coaches are expected to lead their teams to victory. If a team is not performing as expected, it is often the coach who is blamed, especially on a professional level. Research indicates that psycho-emotional factors, stress and emotions are related to voice problems, and these issues have also been found to have a negative impact on voice production by altering the individual's phonation pattern. ${ }^{19-21}$ Research investigating soccer coaches' voice problems is limited. To our knowledge, it seems that only three studies have explored the voice use of soccer coaches. ${ }^{16}$, ${ }^{18,22}$ Gorham-Rowan et $\mathrm{al}^{16}$ studied five soccer coaches to evaluate whether a four-week voice education program was of benefit to their vocal health. The coaches' answered to the Voice Handicap Index (VHI), which is a psychometrically validated questionnaire for measuring the psychosocial handicapping effects of voice disorders. ${ }^{23}$ At the start of the training program, each participant reported vocal symptoms such as hoarseness, temporary voice loss, vocal 
straining and vocal fatigue. One month after the intervention, four of the five participants reported an improvement in vocal quality and an improved ability to maintain their vocal quality during and after a game. ${ }^{16}$

O’Neill and McMenamin ${ }^{22}$ explored the daily experiences of professional soccer coaches' occupational voice use. The study population consisted of five male professional soccer coaches. The results showed that vocal symptoms were common, especially during a match and immediately thereafter. The participants reported hoarseness, loss of voice, croakiness, strained voice, and feelings of tightness around the throat. O'Neill and McMenamin $^{22}$ noted that the coaches shouted during matches and used their voice for long periods. During coaching, they also experienced much psycho-emotional stress.

Buckley et al ${ }^{18}$ examined the occupational voice use and vocal health of 12 elite soccer coaches by a mixed methods approach. Acoustical measurements of the coaches voice use during training sessions was examined with Ambulatory Phonation Monitor (APM) and the vocal symptoms were investigated with Voice Capability Questionnaire (VCQ). Also, semi structured interviews one-on-one with the researcher were completed with the aim of clarifying issues concerning soccer coaches' awareness of their occupational voice use, their vocal health experiences, and the methods they used to manage their voices. The results from the APM measurements showed that the coaches mean perception phonation time during training sessions was $19.25 \%(\mathrm{SD}=4.9 \%)$ and their mean vocal intensity during training sessions was 83.67dB SPL (SD 10.25dB SPL). Across the participant group, the mean fundamental frequency was $150 \mathrm{~Hz}(\mathrm{SD}=30.5 \mathrm{~Hz})$ during training sessions. Based on these parameters, Buckley et $\mathrm{al}^{22}$ concluded that training players is a very vocally demanding task. The results from VCQ showed that all participants had heavy vocal loads during training sessions and reported experiencing vocal symptoms at least some of the time while coaching. Consistent with other vocally demanding occupations, the most frequently reported vocal symptoms among the coaches were hoarseness and vocal fatigue. ${ }^{5,6,24}$ The results from the interviews showed that coaches acknowledged that their voice use was critical for coaching success, but despite this critical reliance, coaches rarely take in to consideration their voice use or vocal health to any degree.

In summary, present research indicates that voice problems are common among sports coaches. ${ }^{18,22}$ Unfortunately, data directly investigating soccer coaching and voice problems are scarce. Previous studies have obtained only small numbers of participants $(N=$ 5-12) and these studies have mainly focused on exploring the vocal health and the pattern of voice use among soccer coaches. Voice problems have been defined in various ways and have 
also been termed differently (e.g. voice disorders or voice problems) in previous literature. ${ }^{4,6}$, 10,13, 25 The term voice problems was deemed appropriate to use in this study, since no perceptual assessment of the participants voices was performed. The aim of this study was to determine the prevalence of voice problems among soccer coaches and identify risk factors which can contribute to voice problems in this particular occupation.

\section{MATERIALS AND METHODS}

\section{Participants}

The target population for the present study were the members of the soccer coaches association in Finland, Suomen Jalkapallovalmentajat, ry (SJV). Contact was made with the chairman of SJV. The chairman distributed a mass e-mail to all members of the association. Participation in the study was voluntary, and anonymity when reporting the results was guaranteed to the participants. Approval to conduct the study was given by the Ethics Committee of the Department of Psychology at Abo Akademi University. The total number of members in SJV was about 500 of which less than $1 \%$ were female. Overall, the response rate was $21.8 \%$ and all $(N=109)$ respondents were males. Their mean age was $44.81(S D 9.56$, age range: $18-69$ years).

On average, the participants had worked 16.36 years (range: $1-50$ years) as soccer coaches. The participants were heterogeneous in terms of how they exerted the soccer coach occupation. For $25.7 \%(n=28)$, soccer coaching was a paid full-time occupation, for $33.9 \%(n=37)$ a paid-part time occupation, and for $40.4 \%(n=44)$ coaching was an unpaid hobby which they carried out in their leisure time. The majority of the participants, $67 \%(n=$ 73), had a main occupation alongside soccer coaching. These participants represented a variety of different occupations. Common occupations were salesmen, teachers, military personal, office workers and engineers. The sample included seven participants who neither coached full-time nor had a main occupation. Of these participants, five coached in their leisure time and two participants coached on a paid part time basis.

\section{Data collection}

The data were obtained with an electronic questionnaire containing multiple-choice (two, three, or four answering alternatives) and open-end questions, which was designed for this study. The questionnaire was self-explanatory, and no explanations or definitions were provided. The questions chosen were based on previous studies on voice problems in various 
populations.7, 9, 13, 26, 27 Questions regarding issues of vocal behaviour, health-related risk factors, psycho-emotional risk factors and environmental risk factors were explored. Questions on vocal symptoms occurring during the past year were also asked. The vocal symptoms were voice becomes strained or tires, voice becomes low or hoarse, voice breaks while talking, difficulty in being heard, throat clearing or coughing while talking, and sensation of pain or lump in the throat. The frequency alternatives for the occurrence of the symptoms were daily, weekly, seldom, or never.

\section{Statistical analysis}

IBM SPSS Statistics 21 software was used for the statistical analyses. Cross tabulations and chi-square tests were used to perform bivariate analyses between selected variables. Not all participants answered all the questions. When reporting percentages, percentages of the total sample who answered the questions were used, and those participants were excluded from the calculations who did not reply the questions. Therefore, the reporting of outcomes is not exactly $100 \%$ in some calculations and consequently the number of participants varies in the results. The correct numbers are shown in the text and tables.

The prevalence of the different vocal symptoms was coded into two categories so that the symptoms that occurred daily or weekly formed a category, called frequently occurring symptoms, and less frequently or not at all occurring symptoms formed a category called less often or not at all occurring symptoms. These variables were used based on previous studies in which the same symptoms have been investigated. 7, 9, 13, 26, 27

Those participants who responded affirmatively when asked whether they had a main occupation alongside coaching answered on an additional question about their main occupation. These participants were classified into two categories so that those who had voice demanding occupations alongside coaching formed a category called vocally demanding main occupation, and those who did not have vocally demanding occupations alongside coaching formed a category called less vocally demanding main occupation. The classification was based on previous research on occupations and voice use. ${ }^{28,29}$ 


\section{RESULTS}

\section{Prevalence of voice problems}

Of the participants, $28.4 \%(n=31)$ had two or more frequently occurring vocal symptoms while $57.8 \%(n=63)$ reported that they had seldom or never occurring vocal symptoms. $13.8 \%(n=15)$ reported one frequently occurring vocal symptom. The most common symptoms were throat clearing or coughing while talking, reported by $30.3 \%(n=33)$, the voice becomes low or hoarse reported by $23 \%(n=25)$ and the voice becomes strained or tires reported by $22 \%(n=24)$ of the participants (Table 1$)$.

Table 1

\begin{tabular}{lccccc}
\hline The frequency of the six vocal symptoms in the whole population $(N=108-109)$ & & \\
\hline & \multicolumn{2}{c}{$\begin{array}{c}\text { Frequently occurring } \\
\text { symptoms }\end{array}$} & & \multicolumn{2}{c}{$\begin{array}{c}\text { Seldom or never occurring } \\
\text { symptoms }\end{array}$} \\
\cline { 2 - 4 } Vocal symptoms & $n$ & $\%$ & & $n$ & $\%$ \\
\hline Throat clearing or coughing while talking & 33 & 30.3 & & 75 & 68.8 \\
The voice becomes low or hoarse & 25 & 23 & & 84 & 77 \\
The voice becomes strained or tires & 24 & 22 & & 85 & 78 \\
Voice breaks while talking & 17 & 15.6 & & 91 & 84.3 \\
Sensation of pain or lump in the throat & 15 & 13.8 & & 94 & 86.3 \\
Difficulty in being heard & 14 & 12.9 & & 95 & 87.1 \\
\hline
\end{tabular}

The proportion of participants who had sought help from health care professionals because of their voice problems was $3.3 \%(n=3)$. These participants had subsequently been diagnosed with a voice disorder by a physician, and one of the participants reported having been compelled to go through a vocal fold surgery because of his voice problems. Participants were asked to answer whether they had been compelled to be absent from the coaching tasks because of their voice problems. Altogether $87.2 \%(n=95)$ reported that they had never been absent, whereas $9.2 \%(n=10)$ reported having been absent less often than once a year and $3.7 \%(n=4)$ reported that they have been compelled to be away from the coaching tasks once a year.

Altogether $46.9 \%(n=15)$ of those who had a vocally demanding main occupation alongside coaching had two or more frequently occurring symptoms, and $15.4 \%$ $(n=6)$ of the participants who had a less vocally demanding main occupation alongside coaching had two or more frequently occurring symptoms, whereas $25.0 \%(n=7)$ of the participants who were paid full-time soccer coaches, and without any other occupation alongside coaching had two or more frequently occurring symptoms (table 2). There was a 
significant association between the form participants exerted the coaching occupation and frequently occurring vocal symptoms $\left(\chi^{2}(4)=10.016, p=.04\right)$. Participants with a vocally demanding occupation alongside coaching were more likely to have vocal symptoms than the other participants.

Table 2

Prevalence of vocal symptoms in full time soccer coaches, soccer coaches with vocally demanding occupations alongside coaching and soccer coaches with less vocally demanding occupation alongside coaching $(N=99)$

\begin{tabular}{|c|c|c|c|c|c|c|}
\hline & \multicolumn{2}{|c|}{ No symptom } & \multicolumn{2}{|c|}{ One symptom } & \multicolumn{2}{|c|}{ Two or more symptoms } \\
\hline & $\%$ & $n$ & $\%$ & $n$ & $\%$ & $n$ \\
\hline Coaching on full time & 64.3 & 18 & 10.7 & 3 & 25.0 & 7 \\
\hline $\begin{array}{l}\text { Vocally demanding occupation alongside } \\
\text { coaching }\end{array}$ & 37.5 & 12 & 15.6 & 5 & 46.9 & 15 \\
\hline $\begin{array}{l}\text { Less vocally demanding occupation } \\
\text { alongside coaching }\end{array}$ & 69.2 & 27 & 15.4 & 6 & 15.4 & 6 \\
\hline
\end{tabular}

\section{Health-related and psycho-emotional risk factors and their relationship with vocal symptoms}

The most common health-related risk factor was chronic rhinitis, occurring in $23.9 \%(n=26)$ of the participants. Respiratory allergies occurred in $10.1 \%(n=11)$ while $4.6 \%(n=5)$ of the participants reported that they had been diagnosed with reflux. Of the participants, $3.7 \%(n=$ 4) reported that they had asthma whereas $4.6 \%(n=5)$ reported using medication for asthma. Of the participants who had chronic rhinitis, $28.4 \%(n=31)$ had two or more frequently occurring symptoms and $13.8 \%(n=15)$ had one frequently occurring symptom. The association between chronic rhinitis and frequently occurring vocal symptoms was significant $\left(\chi^{2}(2)=12.130, p=.002\right)$.

The participants were also asked to answer questions whether the coaching tasks affected their psycho-emotional well-being. Of the participants, 33.9\% $(n=37)$ reported that they felt exhausted because of the coaching tasks. Stress because of the coaching tasks was reported by $32.1 \%(n=35)$ and feeling of fatigue because of the coaching tasks was reported by $28.4 \%(n=31)$ of the participants. There was a significant association between stress and 
frequently occurring vocal symptoms (table 3). Participants who experienced feelings of stress because of the coaching tasks were more likely to have vocal symptoms than the other participants.

Of the study population, $9.2 \%(n=10)$ were smokers. Smoking did not have a significant association with frequently occurring vocal symptoms.

Table 3

\begin{tabular}{|c|c|c|c|c|c|}
\hline \multicolumn{6}{|c|}{ The connections between vocal symptoms and psycho-emotional risk factors $(N=109)$} \\
\hline \multirow{2}{*}{$\begin{array}{l}\text { Psycho-emotional } \\
\text { risk factors }\end{array}$} & \multicolumn{2}{|c|}{$\begin{array}{l}\text { Frequently occurring } \\
\text { symptoms }\end{array}$} & \multicolumn{2}{|c|}{$\begin{array}{l}\text { Seldom or never occurring } \\
\text { symptoms }\end{array}$} & \multirow[t]{2}{*}{$\chi^{2}$} \\
\hline & $n$ & $\%$ & $n$ & $\%$ & \\
\hline Stress & 15 & 48.4 & 20 & 25.6 & $\chi 2(2)=7.044, p=.030$ \\
\hline Exhaustion & 10 & 32.3 & 27 & 34.6 & NS \\
\hline Fatigue & 11 & 35.5 & 20 & 25.6 & NS \\
\hline
\end{tabular}

Abbreviations: NS, not significant

\section{Environmental factors and their impact on the prevalence of vocal symptoms}

Participants were asked to answer questions about their workplace environment during coaching. Altogether 64.5\% $(n=69)$ reported that they weekly or more often coached in areas were the background noise was loud, 63.3\% $(n=69)$ reported that they weekly or more often coached in areas where it felt drafty, and 56\% $(n=61)$ reported that they weekly or more often coached in reverberating environments (Table 4). Regarding the frequently occurring vocal symptoms, no significant association was observed between the vocal symptoms and the environmental factors surveyed. 
Table 4

Reported prevalence of environmental factors in the coaching environment divided into categories weekly or more often and more seldom $(N=108-109)$

\begin{tabular}{lcccc}
\hline & \multicolumn{2}{l}{$\begin{array}{l}\text { Weekly or more } \\
\text { often }\end{array}$} & & More seldom \\
\cline { 2 - 5 } & $\%$ & $n$ & $\%$ & $n$ \\
\hline $\begin{array}{l}\text { Coaching in loud background } \\
\text { noise }\end{array}$ & 64.5 & 69 & 35.5 & 38 \\
$\begin{array}{l}\text { Coaching in areas where it } \\
\text { feels drafty }\end{array}$ & 63.3 & 69 & 36.7 & 40 \\
$\begin{array}{l}\text { Coaching in reverberating } \\
\text { environments }\end{array}$ & 56 & 61 & 44 & 48 \\
$\begin{array}{l}\text { Coaching in areas where the } \\
\text { air feels dry }\end{array}$ & 51.4 & 56 & & 52 \\
$\begin{array}{l}\text { Coaching in areas where the } \\
\text { air quality is poor }\end{array}$ & 37.6 & 41 & 61.5 & 67 \\
\hline
\end{tabular}

The participants were also asked about their voice use more specifically related to their particular work environment (Table 5). Altogether 67\% $(n=73)$ of the participants reported that they were compelled to shout during coaching and $15.6 \%(n=17)$ reported that they had problems getting their voice heard during training sessions. Of those who reported problems getting their voice heard during training sessions, $58.8 \%(n=10)$ reported two or more frequently occurring symptoms, compared to $23.3 \%(n=21)$ of those who did not report that they had problems having their voice heard during coaching. There was a significant association between problems getting the voice heard during coaching and frequently occurring vocal symptoms $\left(\chi^{2}(2)=13.014, p=.001\right)$. Participants who had problems getting their voice heard were more likely to have vocal symptoms than the other participants. There was no significant association between shouting during coaching and frequently occurring vocal symptoms. 
Table 5

Overview of the participants' voice use during coaching in their work environment $(N=105-107)$

\begin{tabular}{|c|c|c|c|c|}
\hline Voice use and symptoms during coaching & & & & \\
\hline & $n$ & $\%$ & $n$ & $\%$ \\
\hline Shouting during coaching & 73 & 67 & 34 & 31.2 \\
\hline Overstrained voice after a match or a training session & 61 & 56 & 44 & 40.4 \\
\hline Problems getting the voice heard during training sessions & 17 & 15.6 & 90 & 82.6 \\
\hline
\end{tabular}

Of the participants, 56\% $(n=61)$ reported that their voice had become overstrained after a match or a training session. Those participants who answered affirmatively to this question, were asked to estimate in which situation their voice became most overstrained. The results showed that $40.4 \%(n=44)$ reported that their voice became most overstrained during training sessions, $11.9 \%(n=13)$ reported that their voice became most overstrained during matches and $1.8 \%(n=2)$ reported that their voice became most overstrained during conferences, e.g. before or after a match. Of those who reported that their voice became overstrained after a match or a training session, $44.3 \%(n=27)$ reported two or more frequently occurring symptoms, compared to $6.8 \%(n=3)$ of those who did not report that their voice became overstrained. The association between frequently occurring vocal symptoms and overstrained voice after a match or training session was significant $\left(\chi^{2}(2)=\right.$ $30.720, p<.001)$.

\section{Other factors with potential impacts on voice problems}

Participants answered a question whether they had received information about voice ergonomics during their coaching education. The results showed that $8.3 \%(n=9)$ reported that they had received such information, and 89.9\% $(n=98)$ had not. Those who had received information were asked to answer an additional question concerning how many hours they had received information about voice ergonomics. The majority of them, 77.8\% $(n=7)$, responded that they received five hours or less, one participant responded he had received information between 5-10 hours and one participant had received 10 hours or more.

The participants were asked to answer which means they used to communicate during coaching. The most common means was body language and gestures which were used 
by $81.7 \%(n=89)$ of the participants. Using a whistle or whistling using fingers were also common, $59.6 \%(n=65)$ of the participants reported that they used whistles during coaching. No participant reported using voice amplifiers such as microphones or megaphones during coaching.

\section{DISCUSSION}

The aim of this study was to determine the prevalence of voice problems among soccer coaches. Six vocal symptoms were explored. Voice problems were considered notable if two of the symptoms occurred weekly or more often. Research on has shown that those who have two or more frequently occurring vocal symptoms often have visible changes on the vocal folds. ${ }^{13,30}$

According to Verdolini and Ramig, ${ }^{4} 3-9 \%$ of the general population is assumed to have voice problems. The results of the present study showed that $28.4 \%$ of the soccer coaches had two or more frequently occurring symptoms indicating that they had far more voice problems than the general population. Studies have shown that women have significantly more voice problems than men. ${ }^{4,6,15}$ Therefore, the results of this study should preferably be compared with men only. Studies investigating male teachers have shown prevalence rates of voice problems between $12-26 \% .5,20,21,27$ The same vocal symptoms as in the questionnaire of the present study were inquired in a study on teachers by Simberg et $\mathrm{al}^{27}$ and the results showed that $19 \%$ of the male teachers $(n=340)$ had voice problems. In a recent study on voice problems in priests by Hagelberg and Simberg, ${ }^{26}$ the results showed that $20.8 \%$ of the male priests $(n=467)$ had voice problems. The results of this study imply that soccer coaches may have more voice problems than teachers and priests, who are considered to have traditional vocally demanding occupations.

The most frequently occurring vocal symptoms in this study were throat clearing or coughing, the voice becomes low or hoarse and the voice gets strained or tires. The symptom throat clearing and coughing occurred in $30.3 \%$ of the participants. This is consistent with the results of previous studies on other vocally demanding occupations. ${ }^{25,26,31}$ The symptom voice becomes low or hoarse occurred in $23 \%$ of the participants. In Nerrière et $\mathrm{al}^{21}$ the results showed that the symptom hoarseness occurred in $10.1 \%$ of the examined male teachers and in Hagelberg and Simberg ${ }^{26}$ the corresponding symptom occurred in $14.8 \%$ of the examined male priests. In Devadas and Rajashehkars ${ }^{31}$ study hoarseness occurred in $16 \%$ of the male telemarketers. Hoarseness is a common symptom of voice problems and appears 
to be present to a greater degree among soccer coaches compared to teachers, priests and telemarketers.

The least frequently occurring vocal symptom in this study was difficulty in being heard which occurred in $12.9 \%$ of the participants. In Hagelberg and Simberg, ${ }^{26}$ the symptom occurred in $5.2 \%$ of the male priests. This symptom appears to occur more often in soccer coaches than in priests. Although difficulty in being heard was the least frequently occurring symptom in this study, it is a vocal symptom that has an overwhelming impact for coaches' occupational success. Soccer coaches have a critical reliance of their voice use during coaching ${ }^{18}$ and if their voice is not heard, it means that they cannot communicate with the players in a way they should.

The results of this study showed that $46.9 \%$ of the participants who had a vocally demanding occupation alongside soccer coaching had two or more frequently occurring vocal symptoms significantly more often than the other participants. The participants' vocally demanding occupations were, for instance, lawyers, salesmen, teachers, military officers and nurses. Previous research has confirmed that persons working in these occupations have more voice problems compared to a general population. $6,13,28,32-34$ Therefore, it is not surprising that the participants who had a vocally demanding occupation alongside coaching also had more voice problems, since they obviously use heavy vocal loads in their main occupations, as well as during coaching.

Of the participants in this study, $23 \%$ reported that they had chronic rhinitis. The prevalence of chronic rhinitis is assumed to be between $20-54 \%$ in the global population. ${ }^{35-38}$ In Finland, it is estimated that between $21-30 \%$ of the people have chronic rhinitis. ${ }^{39,40}$ Several previous studies have examined the relationship between chronic rhinitis and voice problems where the results have shown a significant association between them. ${ }^{26,27,30}$ Also in this study, the association between the prevalence of often occurring vocal symptoms and chronic rhinitis was significant. Because soccer coaches, for the most part, coach outdoors where it is windy, and in Finland also usually chilly, it is likely that colds are common which generally are not good for the voice.

Sports coaches work in a profession that is highly performance-critical. For elite sports coaches especially, the future will be decided by one's success in matches. Besides performance requirements, criticism from the media and dissatisfaction from the club's fans and supporters sets coaches to a vulnerable position. In addition, sports coaches have many other responsibilities such as a need to improve the players' physical, mental, technical and tactical abilities. Irregular working hours are also common, often without days off. There is 
some evidence that coaching entails much stress ${ }^{41}$ and research shows that psycho-emotional factors and stress can increase the risk of developing voice problems. ${ }^{19,}{ }^{20,42}$ Stress was common in this study and was reported by $32.1 \%$ of the participants. Moreover, an association between frequently occurring vocal symptoms and stress was found. Based on the results of this study, it appears that the psycho-emotional risk factors undoubtedly are

prominent among soccer coaches. This finding is consistent with previous research. ${ }^{18,22}$

The results of this study confirm that soccer coaches work in vocally demanding environments. Of the participants, $64.5 \%$ reported that they weekly or more often coached in loud background noise. In Hagelberg and Simberg, ${ }^{26} 31.3 \%$ of the priests reported that they spoke in background noise often or quite often. In Smith et $\mathrm{al}^{43}{ }^{42.7 \%}$ of the male teachers reported that they need to speak over background classroom noise. The prevalence of background noise in the present study is high, which obviously is related to the fact that soccer coaches usually are coaching outdoors. Previous research has confirmed that coaching in outdoor environments exposes coaches to loud background noise and is likely to require increased vocal effort. ${ }^{18,22}$

Most of the participants in this study, $89.9 \%$, had not received information about voice ergonomics during their coaching education. It seems that the soccer coaches lack knowledge and are unaware of how to take care of their voice. These results are quite expected if one looks at the results of previous studies of soccer coaches which indicate that coaches rarely consider their voice use or vocal health. ${ }^{18,22}$

\section{CONCLUSIONS}

The results of this study indicate that the prevalence of voice problems among soccer coaches is high and perhaps even higher than for teachers and priests, which are occupations known to have high prevalence's of voice problems. The results also showed that information about voice ergonomics is not a mandatory part of the coaching education in Finland. Given the extent of voice problems and the fact that soccer coaches have a vocally demanding occupation and their voice use is critical for occupational success, it would be extremely important to increase the awareness of voice use among this group. Soccer coaches are in immense need of more information about voice ergonomics during their coaching education. In addition to information about voice ergonomics during coaching education, continuous inservice training courses should be arranged and soccer coaches should possibly also undergo a voice screening. 


\section{References}

1. Vilkman E. Occupational risk factors and voice disorders. Logoped Phoniatr Vocol. 1996;16:137-141.

2. Timmermans B, De Bodt MS, Wuyts FL, et al. Poor voice quality in future elite vocal performers and professional voice users. J Voice. 2002;16:372-382.

3. Williams N. Occupational voice disorders due to workplace exposure to irritants - a review of the literature. Occupational Medicine. 2002;52:99-101.

4. Verdolini K, Ramig LO. Review: Occupational risks for voice problems. Logoped Phoniatr Vocol. 2001;26:37-46.

5. Van Houtte E, Claeys S, Wuyts F, Van Lierde K. The impact of voice disorders among teachers: Vocal complaints, treatment-seeking behavior, knowledge of vocal care, and voice-related absenteeism. J Voice. $2011 ; 25: 570-575$.

6. Roy N, Merrill R, Thibeault S, Parsa R, Gray S, Smith E. Prevalence of voice disorders in teachers and the general population. J Speech Lang Hear Res. 2004;47:281-293.

7. Simberg S, Santtila P, Soveri A, Varjonen M, Sala E, Sandnabba NK. Exploring genetic and environmental effects in dysphonia: A twin study. J Speech Lang Hear Res. 2009;52:153-163.

8. Gray SD, Thibeault SL. Diversity in voice characteristics - interaction between genes and environment, use of microarray analysis. J Commun Disord. 2002;35:347-354.

9. Åhlander VL, Rydell R, Löfqvist A. Speaker's comfort in teaching environments: Voice problems in swedish teaching staff. J Voice. 2011;25:430-440.

10. Vilkman E. Occupational safety and health aspects of voice and speech professions. Folia Phoniatr Logop. 2004;56:220-253. 
11. Lee S, Lao X, Yu I. A cross-sectional survey of voice disorders among primary school teachers in Hong Kong. J Occup Health. 2010;52:344-352.

12. de Medeiros AM, Barreto SM, Assunção AÁ. Voice disorders (dysphonia) in public school female teachers working in Belo Horizonte: Prevalence and associated factors. J Voice. 2008;22:676-687.

13. Sala E, Laine A, Simberg S, Pentti J, Suonpää J. The prevalence of voice disorders among day care center teachers compared with nurses: A questionnaire and clinical study. J Voice. 2001;15:413-423.

14. Cohn JR, Spiegel JR, Sataloff RT. Vocal disorders and the professional voice user: the allergist's role. Ann Allergy Asthma Immunol. 1995;74:363-373.

15. Coyle SM, Weinrich BD, Stemple JC. Shifts in relative prevalence of laryngeal pathology in a treatmentseeking population. $J$ Voice. 2001;15:424-440.

16. Gorham-Rowan M, Iwahashi M, Quattlebaum L, Rivers D. Voice wear and tear: A pilot study of voice care for soccer coaches. Applied Research in Coaching and Athletics Annual. 2004;19:35-51.

17. Trout J, McColl D. Vocal health for physical educators. J Voice. 2007;78:12-14.

18. Buckley K, O’Halloran P, Oates J. Occupational vocal health of elite sports coaches: an exploratory pilot study of football coaches. J Voice. In press 2015:1-8.

19. Kooijman PGC, de Jong, F I C R S, Thomas G, et al. Risk factors for voice problems in teachers. Folia Phoniatr Logop. 2006;58:159-174.

20. Russell A, Oates J, Greenwood KM. Prevalence of voice problems in teachers. J Voice. 1998;12:467-479.

21. Nerrière E, Vercambre M, Gilbert F, Kovess Masféty V. Voice disorders and mental health in teachers: a cross-sectional nationwide study. BMC Public Health. 2009;9:370.

22. O'Neill J, McMenamin R. Voice use in professional soccer management. Logoped Phoniatr Vocol. 2014;39:169-178. 
23. Jacobson B, Johnson A, Grywalski C, Silbergleit A, Jacobson G, Benninger MS. The Voice Handicap Index (VHI) development and validation. Am J Speech-Lang Pat. 1997;6:66-70.

24. Rumbach AF. Vocal problems of group fitness instructors: prevalence of self-reported sensory and auditoryperceptual voice symptoms and the need for preventative education and training. J Voice. 2013;27:524.e11524.e21.

25. Simberg S, Sala E, Rönnemaa A. A comparison of the prevalence of vocal symptoms among teacher students and other university students. $J$ Voice. 2004;18:363-368.

26. Hagelberg AM, Simberg S. Prevalence of voice problems in priests and some risk factors contributing to them. $J$ Voice. In press 2015:1-8.

27. Simberg S, Sala E, Vehmas K, Laine A. Changes in the prevalence of vocal symptoms among teachers during a twelve-year period. $J$ Voice. 2005;19:95-102.

28. Fritzell B. Voice disorders and occupations. Logoped Phoniatr Vocol. 1996;21:7-12.

29. Titze IR, Lemke J, Montequin D. Populations in the U.S. workforce who rely on voice as a primary tool of trade: a preliminary report. $J$ Voice. $1997 ; 11: 254-259$.

30. Simberg S, Laine A, Sala E, Rönnemaa A. Prevalence of voice disorders among future teachers. J Voice. 2000;14:231-235.

31. Devadas U, Rajashehkar B. The prevalence and impact of voice problems in call center operators. J Laryngol Voice. 2013;3:3-9.

32. Smith E, Gray SD, Dove H, Kirchner L, Heras H. Frequency and effects of teachers' voice problems. $J$ Voice. $1997 ; 11: 81-87$

33. Sapir S, Atias J, Shahar A. Symptoms of vocal attrition in women army instructors and new recruits: results from a survey. Laryngoscope. 1990;100:991-994.

34. Dion G, Miller C, Ramos R, O'Connor P, Howard NS. Characterization of voice disorders in deployed and nondeployed US army soldiers. J Voice. 2013;27:57-60. 
35. Sibbald B, Rink E. Epidemiology of seasonal and perennial rhinitis: Clinical presentation and medical history. Thorax. 1991;46:895-901.

36. Konno S, Hizawa N, Fukutomi Y, et al. The prevalence of rhinitis and its association with smoking and obesity in a nationwide survey of Japanese adults. Allergy. 2012;67:653-660.

37. Larsson U, Taft C, Karlsson J, Sullivan M. Gender and age differences in the relative burden of rhinitis and asthma on health-related quality of life-A Swedish population study. Respir Med. 2007;101:1291-1298.

38. Derebery J, Meltzer E, Nathan RA, et al. Rhinitis symptoms and comorbidities in the United States: Burden of rhinitis in America survey. Otoralyngol. 2008;139:198-205.

39. Haahtela T, von Hertzen L, Mäkelä M, Hannuksela M. Kansallinen allergiaohjelma 2008-2018 - Aika muuttaa suuntaa. Suomen Lääkärilehti. 2008;14:9-21.

40. Kilpeläinen M. Asthma and allergic rhinoconjunctivitis among university students: occurrence and risk factors. [Doctoral dissertation]. Turku: Annales Universitatis Turkuensis; 2001.

41. Fletcher D, Scott M. Psychological stress in sports coaches: A review of concepts, research, and practice. $J$ Sports Sci. 2010;28:127-137.

42. Holmqvist S, Santtila P, Lindström E, Sala E, Simberg S. The association between possible stress markers and vocal Symptoms. J Voice. 2013;27:787.e1-787.e10.

43. Smith E, Kirchner HL, Taylor M, Hoffman H, Lemke JH. Voice problems among teachers: Differences by gender and teaching characteristics. Journal of Voice. 1998;12:328-334. 